\title{
Benthic Si flux in a Greenland fjord and the isotopic response to the early diagenesis
}

TONG WANG ${ }^{1}$, KATHARINE R. HENDRY ${ }^{2}$, HONG CHIN $\mathrm{NG}^{2}$ AND JADE HATTON ${ }^{1,3}$

${ }^{1}$ University of Bristol

${ }^{2}$ School of Earth Sciences, University of Bristol

${ }^{3}$ Charles University

Presenting Author: tova.wang@bristol.ac.uk

Nutrients released from shallow sediments are essential for supporting biological production and carbon cycling in coastal and continental shelf regions. Silicon ( $\mathrm{Si}$ ) is one such nutrient, which is crucial for marine biogeochemical cycling, and linked to the global carbon cycle via diatom production. There are a number of key early diagenetic processes controlling the accumulation of Si in pore waters and the return benthic flux of dissolved silicic acid (DSi) into the overlying bottom seawaters. These processes include biogenic silica (BSi) and abiogenic amorphous silica (ASi) dissolution, terrigenous solid dissolution, authigenic mineral precipitation, and adsorption. However, there are still uncertainties surrounding the quantitative study of benthic $\mathrm{Si}$ fluxes, especially in polar fjord systems that are impacted by both nutrient-rich glacial meltwaters and surrounding coastal waters. In this study, we evaluated the benthic Si flux in Ameralik fjord, a land-terminating glacial system in southwest Greenland, using pore water profiles and core incubation experiments. Diagenetic processes regulating the benthic flux are further examined with stable isotopes of pore water DSi, sediment BSi and glacially-derived ASi , and a mass balance model. Our results show that diffusion contributes to nearly $14 \%$ of the total benthic Si flux at our sites. The pore water DSi are isotopically heavy, with the heaviest values occurring in the uppermost part close to the sediment-water interface. These values might suggest the contribution of reverse weathering, authigenic precipitation and metal oxide adsorption in modifying pore water DSi and the benthic Si flux into the fjord. 